\title{
Physico-Chemical Pretreatment of Seawater: Fouling Reduction and Membrane Characterization
}

\author{
H.K. Shon ${ }^{1}$, S.H. Kim ${ }^{1}$, S. Vigneswaran ${ }^{1, *}$, R. Ben Aim $^{2}$, S. Lee ${ }^{3}$ and J. Cho ${ }^{3}$ \\ ${ }^{1}$ Faculty of Engineering, University of Technology, Sydney, Australia \\ ${ }^{2}$ LIPE/INSA, Toulouse, France \\ ${ }^{3}$ Environmental Science and Technology, Gwangju Institute of Science and Technology, Gwangju, Korea \\ *Corresponding author: Tel. +61-2-9514-2614; Fax.+61-2-9514-2633; E-mail: s.vigneswaran@uts.edu.au
}

\begin{abstract}
The pretreatment of raw seawater is necessary to minimize the organic fouling of seawater reverse osmosis (SWRO) membranes. To predict the membrane fouling of the pretreated seawater, the modified fouling index (MFI) with ultrafiltration (UF) was investigated in terms of molecular weight distribution (MWD) and membrane characterization. The study was conducted with seawater drawn from Collioure, France. The concentration of total dissolved solid was $32760 \mathrm{mg} / \mathrm{L}$. The molecular weight (MW) of the initial seawater organic matter (SWOM) ranged from about $14160 \mathrm{Da}$ to $280 \mathrm{Da}$. $\mathrm{FeCl}_{3}$ flocculation removed the majority of SWOM, while PAC adsorption could not remove the lowest MW fraction of organic matter ( 1110, 750 and $280 \mathrm{Da}$ ). The UF membranes with $30 \mathrm{kDa}$ and $100 \mathrm{kDa}$ molecular weight cut-off removed the majority of of organic matter corresponding to the peaks 14160 Da and 6560 Da in Molecular Weight Distribution.
\end{abstract}

The MFI values obtained when using UF membranes of $30 \mathrm{kDa}$ and $100 \mathrm{kDa}$ with MF pretreatment were $19700 \mathrm{~s} / \mathrm{L}^{2}$ and $31000 \mathrm{~s} / \mathrm{L}^{2}$, respectively. The MFI values after pretreatments of $\mathrm{FeCl}_{3}$ flocculation and PAC adsorption significantly decreased to $6900 \mathrm{~s} / \mathrm{L}^{2}$ and 6700 for $30 \mathrm{kDa}$ UF and to $2300 \mathrm{~s} / \mathrm{L}^{2}$ and $2500 \mathrm{~s} / \mathrm{L}^{2}$ for $100 \mathrm{kDa} \mathrm{UF}$, respectively. Some relation does exist for both membranes between the MFI-UF values and $\left(\mathrm{S}_{\mathrm{pb}}\right)$ values obtained during the first peiod of filtration (pore blocking). The pore blocking zone significantly decreased after flocculation and adsorption pretreatment. This suggests that the pore blocking can be used as an indicator to predict membrane propensity. The detailed membrane characterization on the clean and fouled membrane surface after MFI-UF experiments was made in terms of contact angle, zeta potential, functional group and microscopy.

Keywords: Pretreatment; Seawater desalination; Reverse osmosis; Membrane autopsy; Organic Matter

\section{Introduction}

Seawater reverse osmosis (SWRO) desalination is being increasingly emphasized as a strategy for conservation of limited resources of freshwater. Although desalination has been developed for the last few decades, the SWRO operation is still affected by membrane fouling. The membrane fouling of SWRO has a significant impact on operation of desalination plants. The SWRO foulants consist of i) biofouling (48\%), ii) inorganic colloids (18\%), iii) organic compounds (15\%), iv) silicites/silicates (13\%), v) mineral deposits (6\%) and vi) coagulants (5\%) [1]. Organic compounds in seawater consist of particulate organic matter (POM $>0.45 \mu \mathrm{m})$ and dissolved organic matter (DOM $<0.45 \mu \mathrm{m}$ ). The concentration of the organic matter in seawater is relatively low (about $1-3 \mathrm{mg} / \mathrm{L}$ ) and consequently the portion of organic foulant is small in 
comparison with inorganic constituents. However, seawater organic matter (SWOM) is a more difficult problem to be solved in the SWRO as it leads to biofouling. To examine organic fouling on membrane surface, a number of membrane fouling indices have been developed in terms of silt density index (SDI) and modified fouling index (MFI) using microfiltration (MF), ultrafiltration (UF) and nanofiltration (NF) [2-5]

The MFI study has been investigated in correlation with different pretreatment methods and membrane autopsies [3-6]. A reduction in the particulate fouling potential, more than $80 \%$, was observed by MFI-UF with pretreatment [3]. The removal efficiency of ozonation and biological activated carbon filtration using the $\mathrm{MFI}_{0.45}$ test was $60 \%$ and $50 \%$, respectively. The removal efficiencies observed for the $\mathrm{MFI}_{0.45}$ and SDI do not correspond and the $\mathrm{MFI}_{0.45}$ results are considered to be more reliable [3].

Membrane characterization after each MFI experiment is one of the most effective indicators to determine the MFI performance on membrane fouling [7]. Scanning electron microscopy/energy dispersive X-ray (SEM/EDX), atomic force microscopy (AFM), zeta potential, contact angle, pyrolysis-gas chromatography/mass spectrometry (GC/MS) and attenuated total reflectionFourier transform infrared spectroscopy (ATR-FTIR) can be used to better understand the membrane fouling. The zeta potential value is an index of the surface charge of SWRO membranes. ATR-FTIR gives a detailed screen of the molecular functional groups contributing to membrane fouling. SEM/EDX is used for visual investigation of membrane fouling and elemental analysis on foulants. AFM provides information on membrane roughness. Contact angle represents hydrophobicity of the membrane .

In this study, the objectives are to investigate the effect of pre-treatment on SWOM in terms of MFI-UF. Membrane was characterized after each MFI experiment with different pretreatments.

\section{Materials and methods}

\subsection{Seawater}

This study was conducted with seawater drawn from Collioure, France. The characteristics of this seawater are as follows: $\mathrm{pH}=8.14$; conductivity $=48.5 \mathrm{mS} / \mathrm{cm}$; total dissolved solid $=$ $32760 \mathrm{mg} / \mathrm{L}$; dissolved organic matter $=1.78 \mathrm{mg} / \mathrm{L}$.

\subsection{Pretreatment methods}

Flocculation was carried out using an optimum dose of ferric chloride $\left(\mathrm{FeCl}_{3}=4 \mathrm{mg} / \mathrm{L}\right)$ predetermined by standard jar tests. The seawater was placed in a $1 \mathrm{~L}$ container and an optimum dose of ferric chloride was added. The sample was stirred rapidly for 1 minute at $100 \mathrm{rpm}$, followed by 20 minutes of slow mixing at $30 \mathrm{rpm}$, and 30 minutes of settling. The characteristics of the PAC (James Cumming \& Sons Pty Ltd., Australia) are given elsewhere [7]. For the adsorption experiments, PAC was added to $1 \mathrm{~L}$ of seawater and stirred with a mechanical stirrer at $100 \mathrm{rpm}$ for one hour. Membrane filtration used in this study as pretreatment was a dead-end cell type. MF (cellulose ester, Advantec MFA, Inc., USA) with $0.45 \mu \mathrm{m}$ pore size was employed to filter seawater.

\subsection{MFI experimental set-up}


A dead-end filtration unit was used to study the effect of pretreatment on UF membrane fouling. The schematic diagram of filter experimental set-up is shown in Figure 1. New membranes were used in each experiment to avoid the effect of residual fouling and to compare the results obtained under different conditions. Seawater, with and without pretreatment, was pressurized into a flat sheet membrane module (diameter of $47 \mathrm{~mm}$ ). The operating transmembrane pressure was controlled at 2 bar by means of pressure regulating valve. The UF membranes used in this study are shown in Table 1.

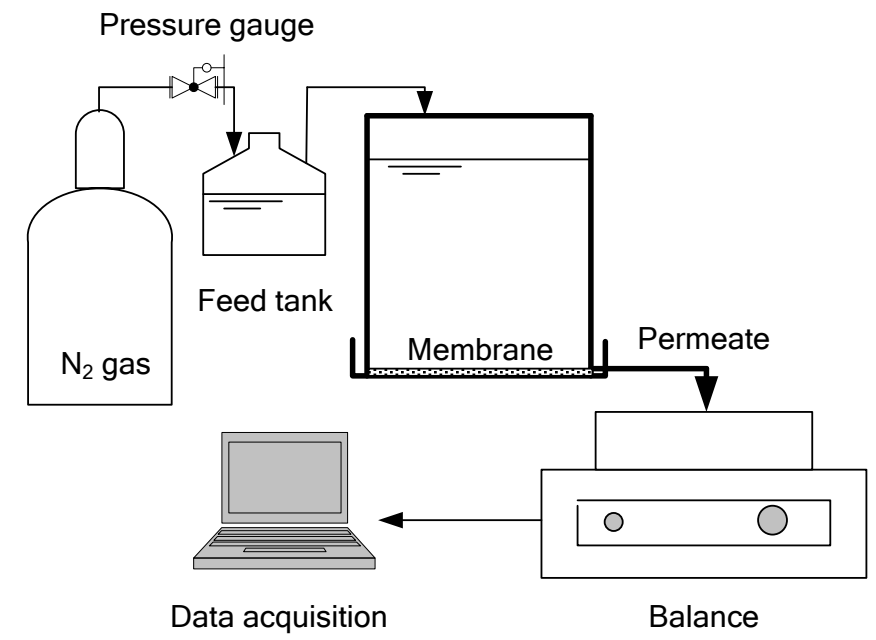

Figure 1 MFI experimental set-up

Table 1 Characteristics of UF membranes used in this study

\begin{tabular}{|c|c|c|c|c|}
\hline Code & Material & MWCO* (Da) & Contact angle $\left({ }^{\circ}\right)$ & Company \\
\hline NTR-7410 & $\begin{array}{l}\text { Sulfonated } \\
\text { polysulfones }\end{array}$ & $20 \mathrm{kDa}$ & 69 & Nitto Denko \\
\hline HFM-100 & $\begin{array}{l}\text { Poly(vinylidene } \\
\text { fluoride) }\end{array}$ & $30 \mathrm{kDa}$ & 94.2 & Koch \\
\hline HFM-180 & $\begin{array}{l}\text { Poly(vinylidene } \\
\text { fluoride) }\end{array}$ & 100 kDa & 92.4 & Koch \\
\hline
\end{tabular}

MWCO: molecular weight cut-off

\subsection{Molecular weight distribution (MWD)}

The seawater after each pretreatment was subjected to MW distribution measurement to investigate SWOM removal. High pressure size exclusion chromatography (HPSEC, Shimadzu, Corp., Japan) with a SEC column (Protein-pak 125, Waters, Milford, USA) was used to determine the MW distributions of SWOM. Standards of MW of various polystyrene sulfonates (PSS: 210, 1800, 4600, 8000 and $18000 \mathrm{Da}$ ) were used to calibrate the equipment.

\subsection{Membrane characterization}

The clean and fouled membrane surfaces after MFI experiments were analyzed for functional groups using attenuated total reflection-Fourier transform infrared spectroscopy (ATR-FTIR). The fouled membranes were examined by FTIR (460 plus, Jasco, Japan) equipped with an ATR accessory. Contact angle measurements were made using the sessile drop method with a contact angle meter (Tantec, Co., USA). These values were used to determine the index of membrane hydrophobicity; $20 \mu \mathrm{L}$ of Milli-Q water was dropped onto the dried membrane 
surface and the contact angle was measured within approximately 10 seconds. SEM/EDX (FE-SEM S-4700, Hitachi Corp., Japan) was used to investigate the membrane structure and membrane fouling. The voltage was $5 \mathrm{kV}$ and the working distance was $12 \mathrm{~mm}$. Zeta potential on the membrane surfaces was measured by electrophoresis method (ELS 8000 Otzca, Japan) using polylatex in $10 \mathrm{mM} \mathrm{NaCl}$ solution as a standard particle. The $\mathrm{pH}$ of solution was adjusted with $0.1 \mathrm{~N} \mathrm{HCl}$ and $\mathrm{NaOH}$.

\section{Results and discussion}

\subsection{MWD of SWOM after different pretreatments}

To better understand the membrane fouling from SWOM by MFI-UF, it is necessary to know the range of MWD of SWOM removed from the seawater by the pretreatments such as flocculation, adsorption, MF and UF. The MWD of SWOM in seawater was measured after each pretreatment (Figure 2). The MW of the initial SWOM ranged from about 14160 Da to 280 Da with the highest fraction at around $280 \mathrm{Da}$. MW peaks for the seawater was found around 14160 Da, 6560 Da, 1110 Da, 750 Da and 280 Da.

Figure 2 (a) shows the MWD of SWOM after pretreatments of $\mathrm{FeCl}_{3}$ flocculation and PAC adsorption. $\mathrm{FeCl}_{3}$ flocculation removed the majority of SWOM MW except $280 \mathrm{Da}$, while PAC adsorption could not remove 1110, 750 and 280 Da. However, PAC adsorption resulted in a better removal of organic matter of 280 Da MW. Figure 2 (b) presents the MWD of SWOM after it was filtered through UF of molecular weight cut-off sizes of $30 \mathrm{kDa}$ and 100 $\mathrm{kDa}$. Removal of different MWs by both UF membranes showed a similar pattern. The UF membranes removed the majority of $14160 \mathrm{Da}$ and $6560 \mathrm{Da}$. This suggests that when MFI with UF was investigated, the organic matter with 14160 Da and 6560 Da contributed to membrane fouling.

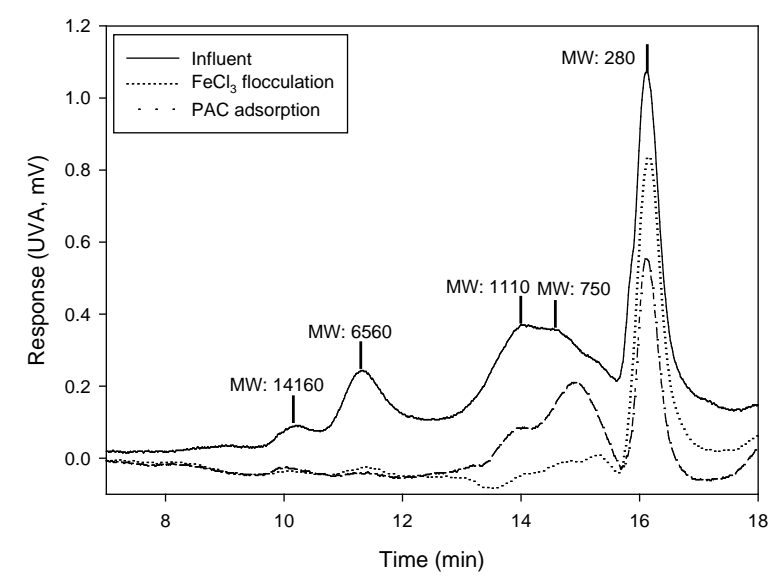

a)

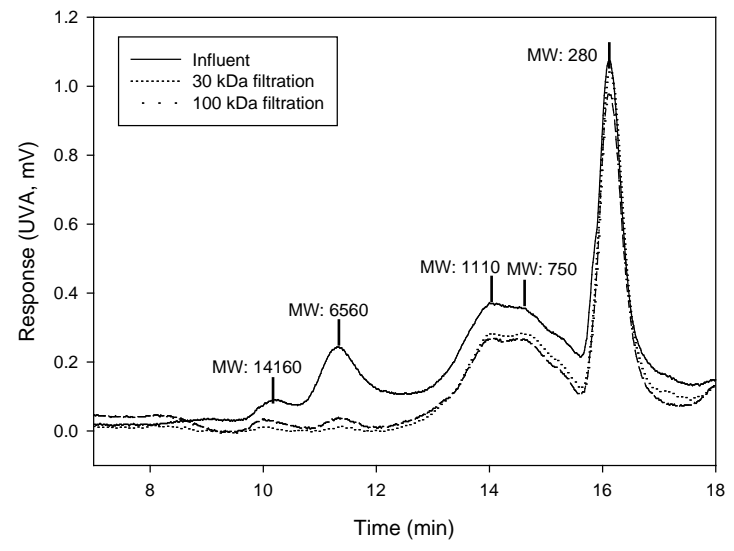

b)

Figure 2 MWD of SWOM after the pre-treatment of (a) $\mathrm{FeCl}_{3}$ flocculation, PAC adsorption $\left(\mathrm{FeCl}_{3}\right.$ dose $=4 \mathrm{mg} / \mathrm{L}$; PAC dose $\left.=0.5 \mathrm{~g} / \mathrm{L}\right)$, (b) $30 \mathrm{kDa}$ UF and $100 \mathrm{kDa} \mathrm{UF}$

\subsection{Modified fouling index (MFI)}

The MFI values using MF is suitable for particulate organic matter ( $>0.45 \mu \mathrm{M})$. However, the MFI-MF neglects the role of colloidal and dissolved matter in seawater which includes the 
majority of dissolved organic matter. The MFI using UF was thus conducted to predict the fouling of dissolved organic matter.

The MFI experiments were conducted using MF $(0.45 \mu \mathrm{m})$ and UF $(20,30$ and $100 \mathrm{kDa}$ MWCO) membranes. A membrane with appropriate MWCO size needs to be selected in terms of pore blocking and cake filtration. Figure 3 (a) shows the permeate volume vs time for MF. The zones of pore bloking and cake filtration were clearly found. Pore blocking occurred during the first 20-min operation. The $30 \mathrm{kDa}$ and $100 \mathrm{kDa}$ UF also showed the zones of pore bloking and cake filtration to calculate a representative MFI. From these graphs, we calculated the MFI which semi-quantitatively represents the dissolved SWOM fouling. In this study, the results obtained with 30 and $100 \mathrm{kDa}$ UF membranes were used to interpret the effect of membrane fouling by dissolved SWOM after different pretreatments.

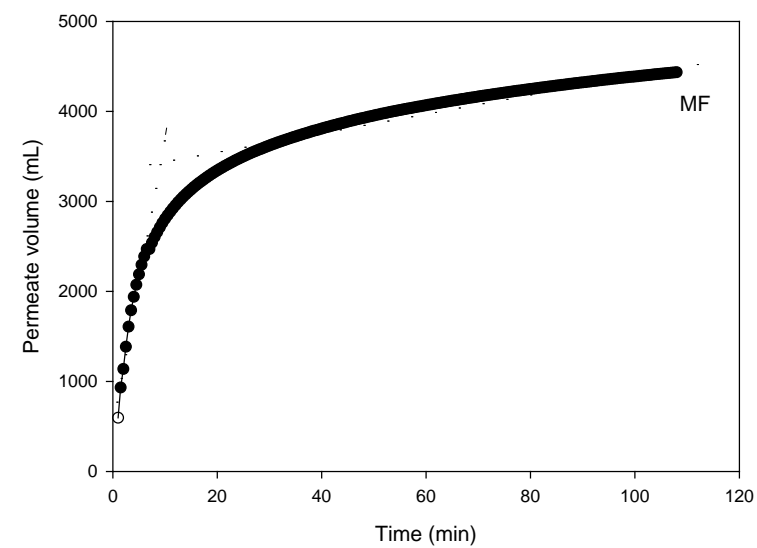

a)

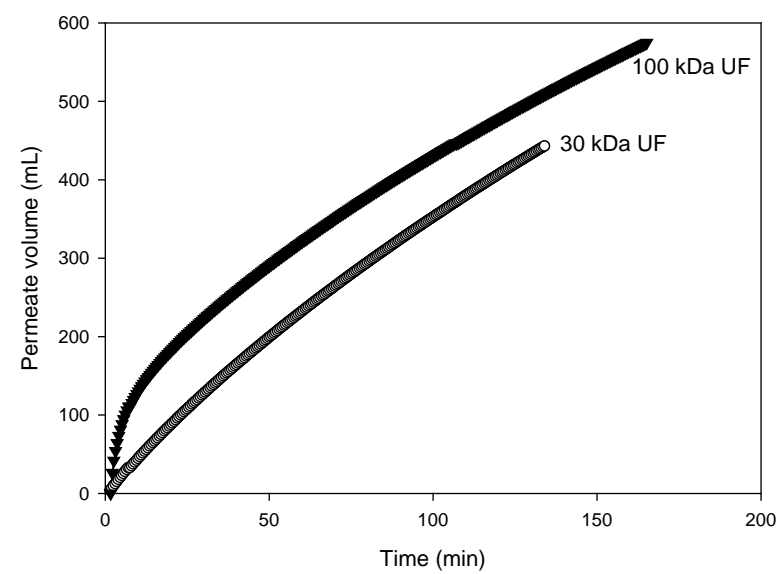

b)

Figure 3 Permeate volume vs time with (a) MF, (b) UF of $30 \mathrm{kDa}$ and $100 \mathrm{kDa}$ (seawater; pressure $=2 \mathrm{bar}$; temperature $=23{ }^{\circ} \mathrm{C}$; diameter of membrane used $=47 \mathrm{~mm}$ )

Figure 4 shows the results of $\mathrm{t} / \mathrm{v}$ vs $\mathrm{v}$ after different pretreatments. Here, $\mathrm{t}$ and $\mathrm{v}$ are filtration time and total permeate volume, respectively. MFI was determined from the slope of the straight line obtained when plotting $\mathrm{t} / \mathrm{v}$ versus $\mathrm{v}$, in agreement with the general cake filtration equation for constant pressure [8].

$$
\frac{t}{v}=\frac{\eta R_{m}}{\Delta P A}+\underset{2 \Delta P A^{2}}{\stackrel{\eta \alpha C_{b}}{2}} v
$$

where,

$v \quad$ total permeate volume (L)

$\mathrm{R}_{\mathrm{m}} \quad$ membrane resistance $(1 / \mathrm{m})$

$\mathrm{t}$ filtration time (s)

$\triangle P \quad$ applied trans-membrane pressure ( $\mathrm{Pa})$

$\eta \quad$ water viscosity at $20^{\circ} \mathrm{C}\left(\mathrm{N} \mathrm{s} / \mathrm{m}^{2}\right)$

$\alpha \quad$ the specific resistance of the cake deposited

$C_{\mathrm{b}} \quad$ the concentration of particles in a feed water $(\mathrm{mg} / \mathrm{L})$

A the membrane surface area $\left(\mathrm{m}^{2}\right)$

MFI cake fouling index $\left(\mathrm{s} / \mathrm{L}^{2}\right)$

The MFI values of $30 \mathrm{kDa}$ and $100 \mathrm{kDa}$ UF after MF pretreatment were $19700 \mathrm{~s} / \mathrm{L}^{2}$ and 
$31000 \mathrm{~s} / \mathrm{L}^{2}$, respectively (Figure 5). The MFI values after pretreatments of $\mathrm{FeCl}_{3}$ flocculation and PAC adsorption significantly decreased to $6900 \mathrm{~s} / \mathrm{L}^{2}$ and 6700 for $30 \mathrm{kDa} \mathrm{UF}$ and to 2300 $\mathrm{s} / \mathrm{L}^{2}$ and $2500 \mathrm{~s} / \mathrm{L}^{2}$ for $100 \mathrm{kDa} \mathrm{UF}$, respectively.

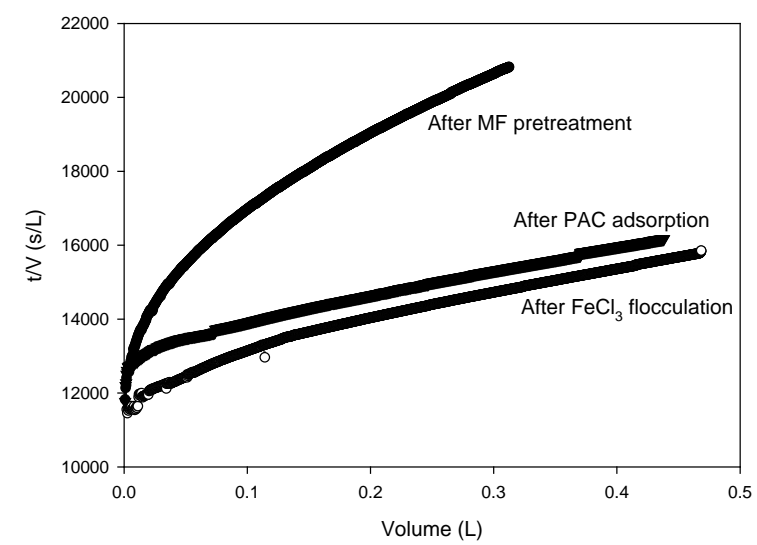

a) UF with $30 \mathrm{kDa}$

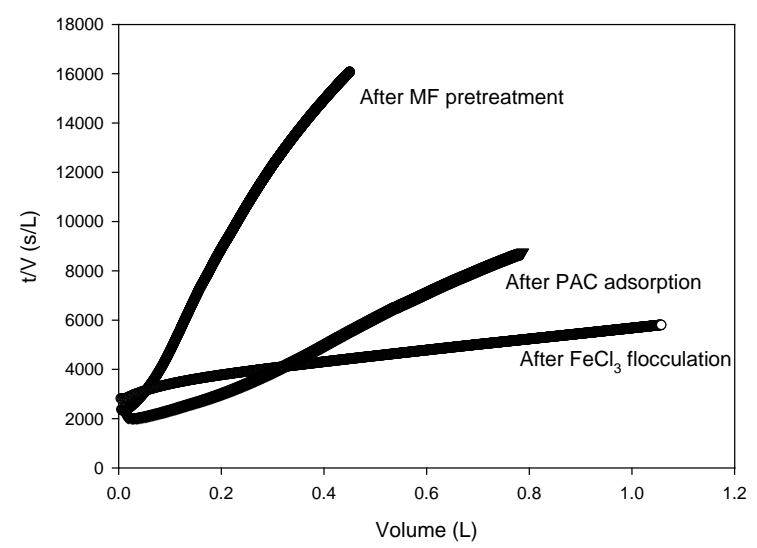

b) UF with $100 \mathrm{kDa}$

Figure $4 \mathrm{t}$ (time) $/ \mathrm{v}$ (permeate volume) vs v after different pretreatments (pressure $=2 \mathrm{bar}$; temperature $=23^{\circ} \mathrm{C}$; diameter of membrane used $=47 \mathrm{~mm}$ )

Figure 5 shows the results of $t / v$ vs $t$ after different pretreatments. The pore blocking slope was determined from the gradient of the general filtration equation at constant pressure using a plot of $\mathrm{t} / \mathrm{V}$ versus $\mathrm{t}$ [9].

$$
\frac{t}{v}=S_{p b} t+b
$$

where,

$v \quad$ total permeate volume (L)

$\mathrm{t} \quad$ filtration time (s)

$\mathrm{S}_{\mathrm{pb}} \quad$ pore blocking slope by critical time - pore blocking index (1/L)

b constant

Table 2 shows the values of $T_{c}, S_{p b}$ and MFI values. Here, $v_{c}$ and $t_{c}$ are defined as the critical values beyond which we could obtaine at linear relation between $t / v$ and $t$ with a correlation coefficient $\left(\mathrm{R}^{2}>0.990\right)$. $\mathrm{S}_{\mathrm{pb}}$ was obtained with the slope of the straight line between $\mathrm{t} / \mathrm{v}$ and $\mathrm{t}$ (from $t=0$ to the critical point). After MF pretreatment, the potential of pore blocking was quite high and there was a correlation between $\mathrm{S}_{\mathrm{pb}}$ and MFI-UF. This could be explained by the fact that the colloidal fraction plays an important role in pore blocking as in the resistance of the cake. Flocculation and adsorption were more efficient than MF for decreasing the MFI (cake filtration index) and $\mathrm{S}_{\mathrm{pb}}$ (pore blocking index). Membranes with smaller molecular weight cutoff are being tested and will allow a more precise comparison of the efficiency of the pretreatment related to pore blocking phenomena. 


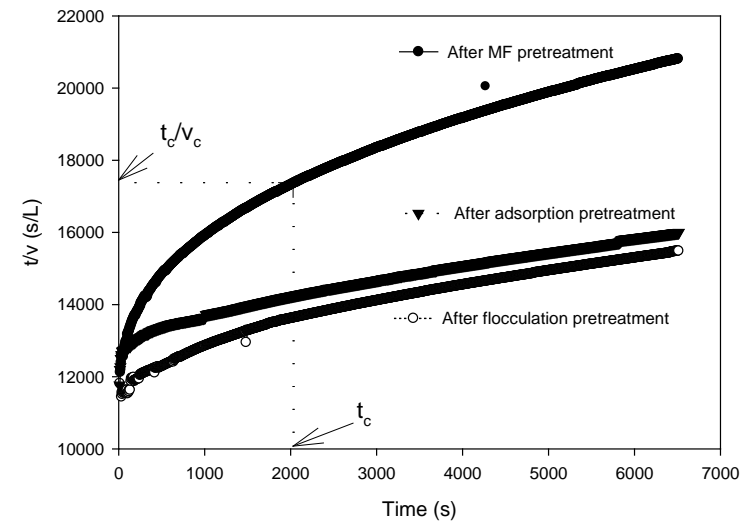

a) UF with $30 \mathrm{kDa}$

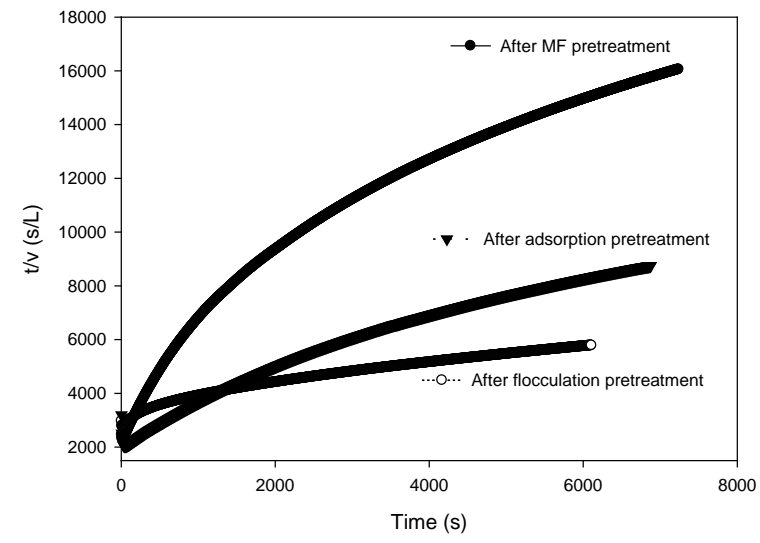

b) UF with $100 \mathrm{kDa}$

Figure $5 \mathrm{t}$ (time) $/ \mathrm{v}$ (permeate volume) vs t after different pretreatments (pressure $=2 \mathrm{bar}$; temperature $=23^{\circ} \mathrm{C}$; diameter of membrane used $=47 \mathrm{~mm}$ )

Table $2 \mathrm{~S}_{\mathrm{pb}}$ values with $30 \mathrm{kDa}$ and $100 \mathrm{kDa}$ membranes after different pretreatments

\begin{tabular}{llllll}
\hline & Pretreatment & $\mathrm{t}_{\mathrm{c}}(\mathrm{s})$ & $\mathrm{t}_{\mathrm{c}} / \mathrm{v}_{\mathrm{c}}(\mathrm{s} / \mathrm{L})$ & $\mathrm{S}_{\mathrm{pb}}(1 / \mathrm{L})$ & MFI-UF $\left(\mathrm{s} / \mathrm{L}^{2}\right)$ \\
\hline UF with & After MF & 2028 & 17300 & 2.191 & 19700 \\
$30 \mathrm{kDa}$ & After flocculation & 1732 & 13600 & 1.18 & 6900 \\
& After adsorption & 961 & 13500 & 1.466 & 6700 \\
\hline UF with & After MF & 2255 & 9900 & 3.286 & 31000 \\
$100 \mathrm{kDa}$ & After flocculation & 1555 & 4200 & 0.857 & 2300 \\
& After adsorption & 1755 & 4700 & 1.563 & 2500 \\
\hline
\end{tabular}

\subsection{Membrane characterization}

\subsubsection{Contact angle and ATR-FTIR spectroscopy}

Contact angle on the clean and fouled UF membranes after MFI-UF experiments was measured for effluent solutions after different pretreatments. A higher contact angle indicates higher hydrophobicity of the membrane surface. The contact angle of clean $30 \mathrm{kDa}$ and 100 $\mathrm{kDa} U \mathrm{UF}$ was $94.2^{\circ}$ and $92.4^{\circ}$, respectively, suggesting that the membranes are hydrophobic in nature (more than $50^{\circ}$ ) (Figure 6). The result of the contact angle of clean and fouled membranes followed the order of clean $\left(94.2^{\circ}\right)>\operatorname{MF}\left(93.6^{\circ}\right)>$ without pretreatment $\left(89.6^{\circ}\right)>$ flocculation $\left(76.1^{\circ}\right)>$ adsorption $\left(75.0^{\circ}\right)$ for $30 \mathrm{kDa}$ UF. For $100 \mathrm{kDa} U \mathrm{UF}$, it was: clean $\left(92.4^{\circ}\right)$ $>\operatorname{MF}\left(91.9^{\circ}\right)>$ flocculation $\left(89.0^{\circ}\right)>$ without pretreatment $\left(84.3^{\circ}\right)>$ adsorption $\left(79.5^{\circ}\right)$. The contact angle of fouled membranes suggested that fouled membranes remained the hydrophobic nature $\left(>50^{\circ}\right)$. 


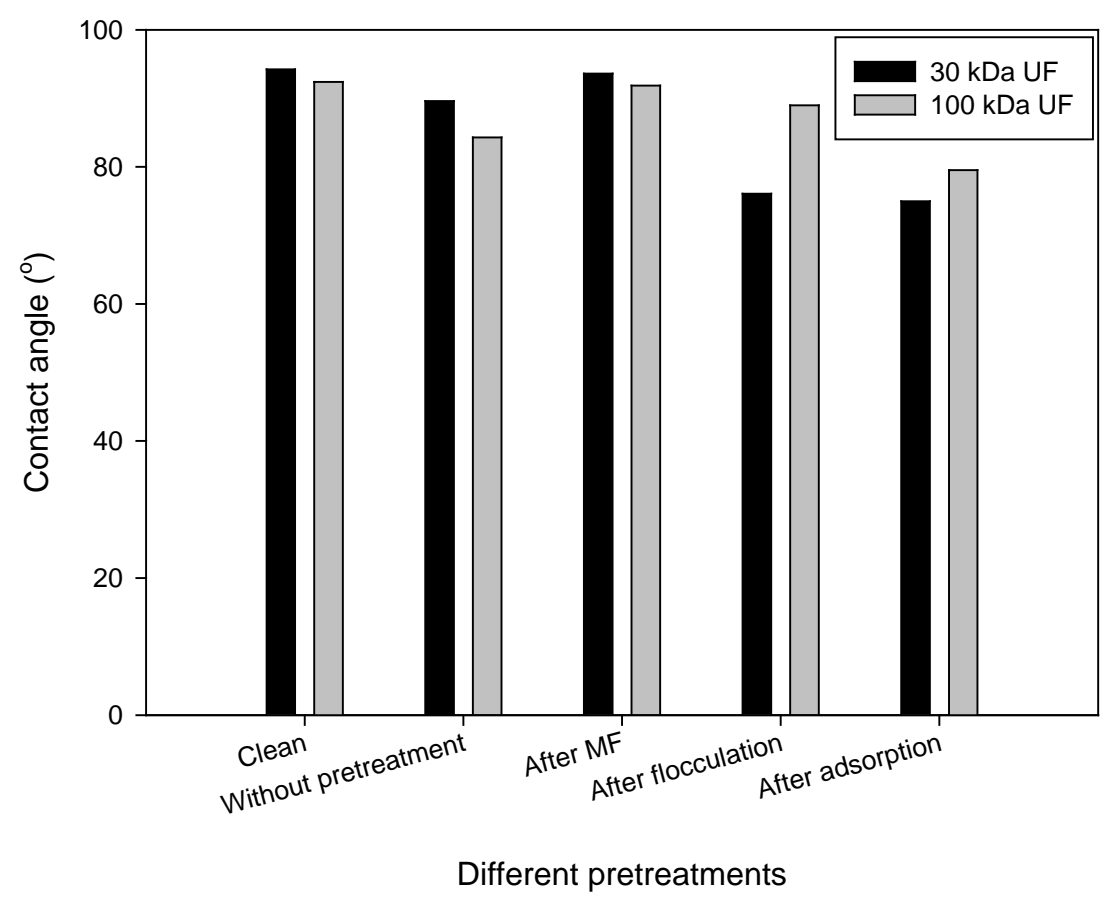

Figure 6 Effect of the contact angle on the clean and fouled membrane surfaces

ATR-FTIR analysis was conducted to investigate the functional groups in the foulants on the clean and fouled membrane surfaces (Figure 7). Both pristine PVDF membranes showed similar functional groups. After UF filtration, all the intensity of the functional groups significantly decreased due to fouling. The fouled membrane without any pretreatment indicated the lowest intensity. However, the intensity after the pretreatments of MF, flocculation and adsorption slightly decreased. With the $100 \mathrm{kDa}$ filtration, only PAC adsorption showed the highest intensity.

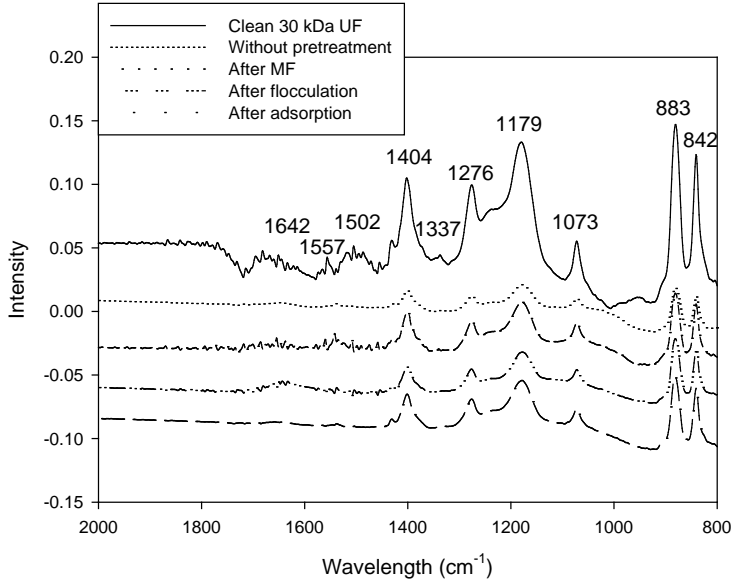

a)

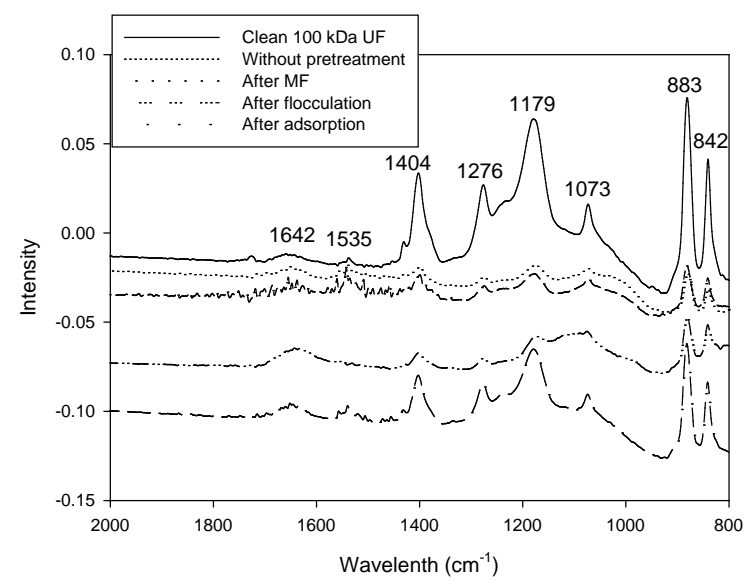

b)

Figure 7 FTIR spectra of UF membranes of (a) $30 \mathrm{kDa}$ and (b) $100 \mathrm{kDa}$ after filtration of effluents of pretreated seawater

\subsubsection{Zeta potential and SEM/EDX}

Figure 8 presents the variation of zeta potential of clean UF membranes after different pretreatments. The isoelectro point (IEP) of UF of $30 \mathrm{kDa}$ and $100 \mathrm{kDa}$ was 2.7 and 2.6, 
respectively. The zeta potential on the fouled membranes decreased after they underwent filtration of pretreated effluents. The growth of the cake layer has been developed with increase in the feed concentration [10]. This weakened the electrokinetic flow owing to a lower permeate flux, thus leading to a decrease of the membrane zeta potential. However, the zeta potential after flocculation pretreatment increased. During $\mathrm{FeCl}_{3}$ flocculation, the iron ions and/or iron hydrolates may have been adsorbed on the membrane surface. This may have caused increase in zeta potential. Even though the same material of two UF membranes was used, the zeta potential was different. This is probably due to different roughness of the membranes. For more detailed investigation, we will confirm the results for the future.

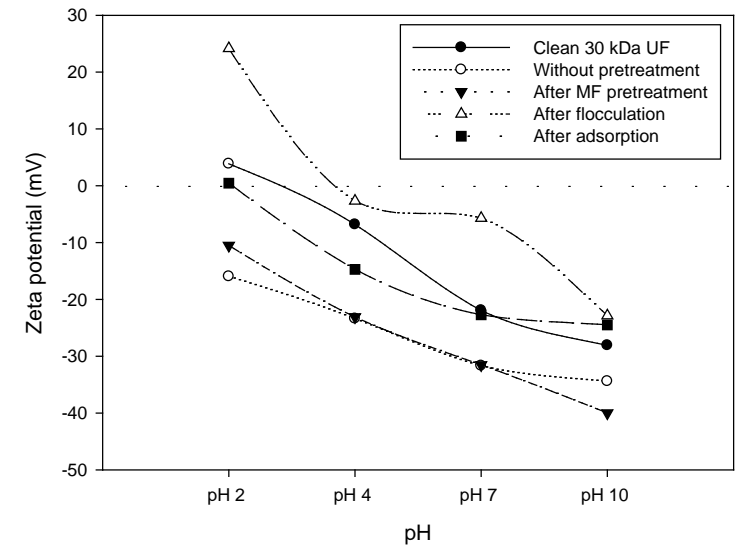

a)

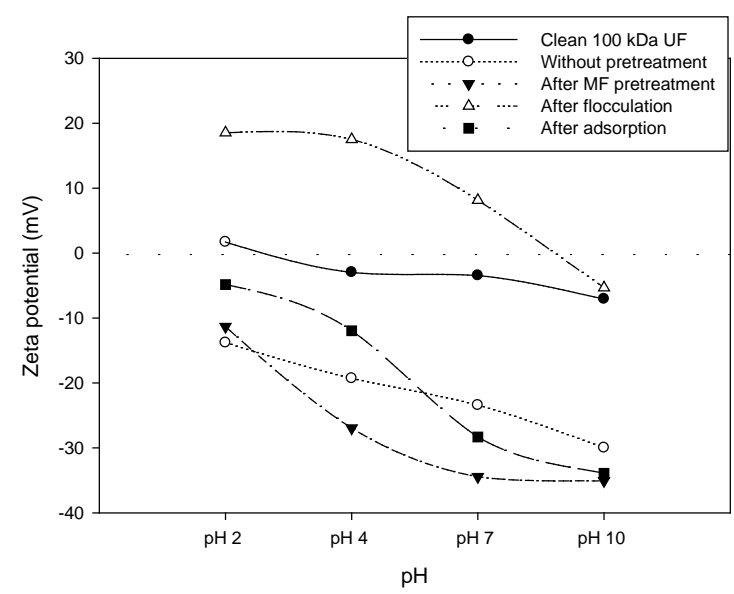

b)

Figure 8 Zeta potential of UF membranes of $30 \mathrm{kDa}$ and $100 \mathrm{kDa}$ as a function of solution $\mathrm{pH}$ (background electrolyte concentration $=10 \mathrm{mM} \mathrm{NaCl}$ )

Figure 9 shows SEM pictures of the UF membranes after they underwent filtration with pretreated effluents. When there was no pretreatment, both membrane surfaces were severely contaminated, while the UF surface was preserved when a pretreatment of adsorption was adopted. The UF membrane surfaces treating the MF pretreated effluent consisted of a majority of the foulants of $1 \mu \mathrm{m}$ grain type. Thick cake layer on the UF surfaces after flocculation was identified. This may be due to iron complexation with SWOM. To investigate detailed elements on the fouled surfaces after flocculation, SEM/EDX analysis was conducted (Figure 10). The clean PVDF membrane consisted of carbon ( $C=56.5 \%)$ and fluorine $(\mathrm{F}=43.5 \%)$. After $\mathrm{FeCl}_{3}$ flocculation pretreatment, the relative fraction of the carbon decreased, while new sodium $(\mathrm{Na})$, magnesium $(\mathrm{Mg})$, chlorine $(\mathrm{Cl})$ and iron $(\mathrm{Fe})$ elements were found in the foulants. The iron (Fe) content on the $30 \mathrm{kDa}$ and $100 \mathrm{kDa}$ UF increased by up to $1.39 \%$ and $4.84 \%$, respectively. This is probably due to the removal on the membrane of residual microflocs present in the supernatant after the coagulation experiment. The significant decrease of carbon peaks on the $100 \mathrm{kDa}$ UF is also due to low penetration of electron beam into membrane because of the foulant layer. 


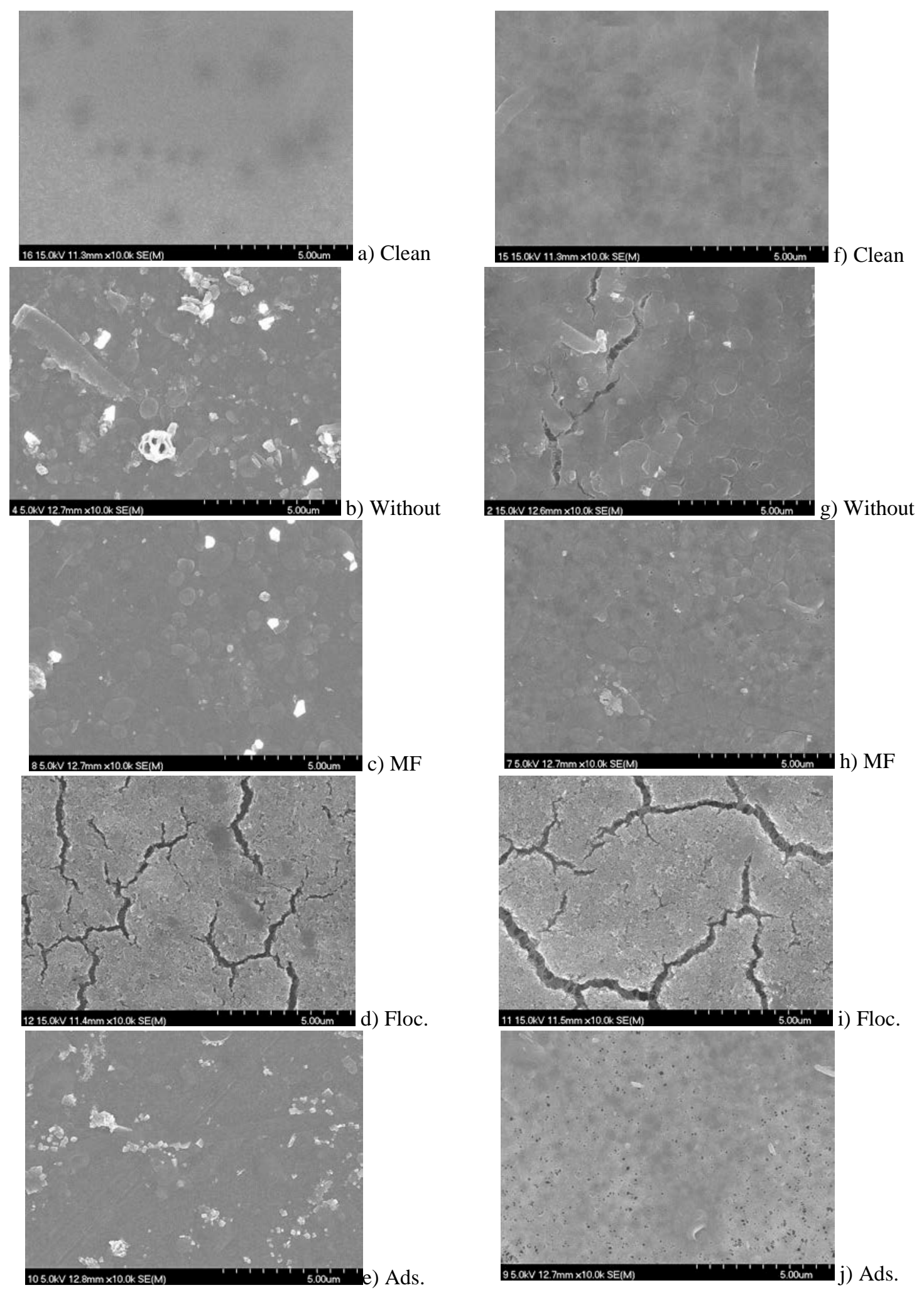

Figure 9 SEM pictures of (a-e) $30 \mathrm{kDa}$ and (f-j) $100 \mathrm{kDa}$ UF membranes after different pretreatments $\left(\mathrm{MF}=\right.$ microfiltration; Floc. $=\mathrm{FeCl}_{3}$ flocculation; Ads. $=$ PAC adsorption) 


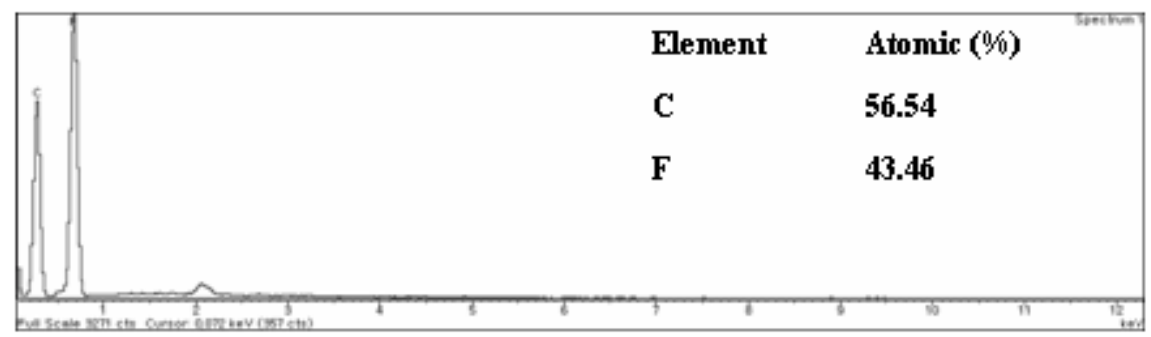

a)

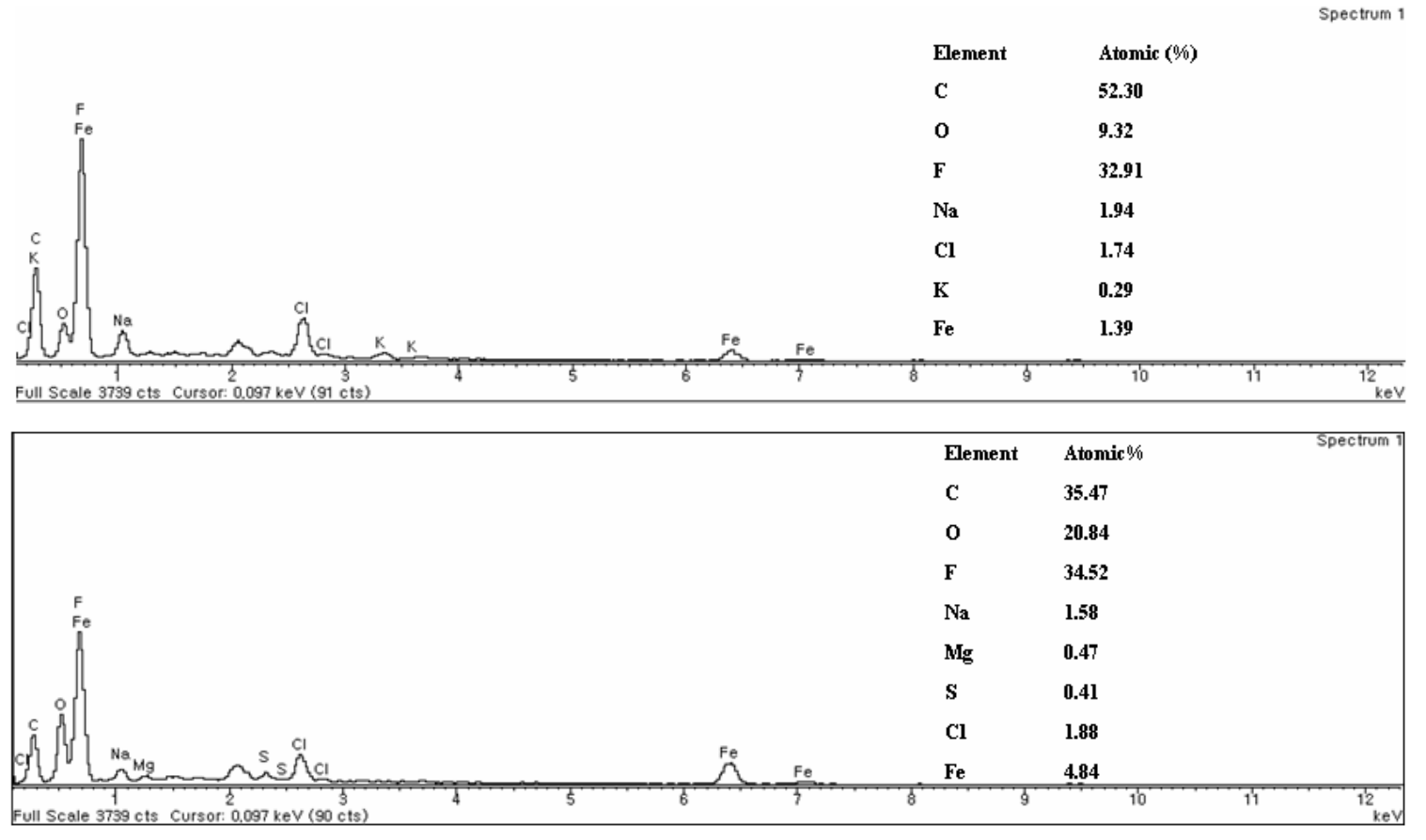

b)

Figure 10 SEM/EDX results on the clean UF (a), $30 \mathrm{kDa}$ (b) and $100 \mathrm{kDa}$ (c) surfaces (after flocculation pretreatment)

\section{Conclusions}

The effect of different physico-chemical pretreatment methods on MFI-UF was investigated. Membrane after each MFI experiment with pretreated seawater effluent was also characterized. The results led to the following conclusions.

1. The MW of the initial SWOM in seawater used ranged from about $14160 \mathrm{Da}$ to $280 \mathrm{Da}$.

2. $\mathrm{FeCl}_{3}$ flocculation removed the majority of SWOM except $280 \mathrm{Da}$, while PAC adsorption could not remove 1110, 750 and 280 Da. Removal of different MWs by both UF membranes (30 and $100 \mathrm{kDa}$ ) showed a similar pattern. The UF membranes removed the majority of $14160 \mathrm{Da}$ and $6560 \mathrm{Da}$.

3. The MFI values of UF of $30 \mathrm{kDa}$ and $100 \mathrm{kDa}$ after MF pre-treatment were $19700 \mathrm{~s} / \mathrm{L}^{2}$ and $31000 \mathrm{~s} / \mathrm{L}^{2}$, respectively. This result to be confirmed shows that a small change in the membrane pore size (about 30\%) is able to modify the characteristics of the cake being formed at the membrane surface. The MFI values after pretreatments of $\mathrm{FeCl}_{3}$ flocculation and PAC adsorption significantly decreased to $6900 \mathrm{~s} / \mathrm{L}^{2}$ and 6700 for $30 \mathrm{kDa} \mathrm{UF}$ and to 2300 $\mathrm{s} / \mathrm{L}^{2}$ and $2500 \mathrm{~s} / \mathrm{L}^{2}$ for $100 \mathrm{kDa} U \mathrm{UF}$, respectively. The MFI-UF values look related to the $\mathrm{S}_{\mathrm{pb}}$ values for both membranes. The pore blocking zone significantly decrased after flocculation 
and adsorption pretreatment. Further experiments are performed with membranes of different (smaller) molecular weight cutoff for bring to get more precise uniformity concering the difference of the low MW fraction of the fouling.

4. The contact angle of UF of clean $30 \mathrm{kDa}$ and $100 \mathrm{kDa}$ was $94.2^{\circ}$ and $92.4^{\circ}$, respectively. The contact angles of fouled membranes were found to be more than $70^{\circ}$, suggesting that the short-term MFI-UF experiments did not change the hydrophobicity of the membranes.

5. After UF filtration, the intensity of the functional groups significantly decreased due to fouling. The fouled membrane without any pretreatment after both UF MFI filtrations indicated the lowest intensity, while the intensity after the pretreatments of MF, flocculation and adsorption slightly decreased.

6. The zeta potential on the membrane decreased during the filtration of the pretreated effluents, while the zeta potential after flocculation pretreatment increased.

7. Both UF membrane surfaces were severely fouled with seawater without pretreatment, while the UF surface was preserved when a pretreatment of adsorption was adopted. Thick cake layer on the UF surfaces after flocculation was identified. The iron (Fe) content on the $30 \mathrm{kDa}$ and $100 \mathrm{kDa} \mathrm{UF}$ increased by up to $1.39 \%$ and $4.84 \%$, respectively.

\section{Acknowledgements}

This research was funded by UTS partnership, DEST-ISL and ARC discovery projects and supported by MEDINA (EU-6 ${ }^{\text {th }}$ frame work) project. This research was in part supported by a grant from the National Research Laboratory Program by the Korea Science and Engineering Foundation (NOM ecology Lab: R0A-2007-000-20055-0). A part of this research was conducted at INSA-Toulouse, France.

\section{REFERENCES}

[1] M.G. Khedr, Membrane fouling problems in reverse osmosis desalination applications, Desalination \& Water Reuse, 10 (2000) 3.

[2] J.C. Schippers and J. Verdouw. The modified fouling index, a method of determining the fouling characteristics of water, Desal., 32 (1980) 137.

[3] S.F.E. Boerlage, M.D. Kennedy, M.P. Aniye, E.M. Abogrean, D.E.Y. El-Hodali, Z.S. Tarawneh and J.C. Schippers. Modified Fouling Index ultrafiltration to compare pretreatment processes of reverse osmosis feedwater. Desal., 131 (2000) 201.

[4] S.F.E. Boerlage, M.D. Kennedy, M.R. Dickson, D.E.Y. El-Hodali and J.C. Schippers. The modified fouling index using ultrafiltration membranes (MFI-UF): characterisation, filtration mechanisms and proposed reference membrane. J. Membr. Sci., 197 (2002) 1.

[5] S. Khirani, R. Ben Aim, M.-H. Manero. Improving the measurement of the Modified Fouling Index using nanofiltration membranes (NF-MFI). Desal., 191 (2006) 1.

[6] D.R. Van der Vaart and E.P. Stahel. An investigation of the modified fouling index as a test for plugging potential of pretreated seawater. Desal., 68 (1988) 45-56.

[7] H.K. Shon, S. Vigneswaran, In S. Kim, J. Cho and H. H. Ngo. Effect of pretreatment on the fouling of membranes: application in biologically treated sewage effluent. J. Membr. Sci., 234 (2004) 111. 
[8] S.F.E. Boerlage, M.D. Kennedy, M.P. Aniye, E.M. Abogrean, G. Galjaaard and J.C. Schippers. Monitoring particulate fouling in membrane systems. Desal., 118 (1998) 131.

[9] S. Khirani, C. Wei, S. Laborie, H.K. Shon, S. Vigneswaran and R. Ben Aim, Fouling index: a new approach. The 6th International Membrane Science and Technology Conference (IMSTEC07), Workshop, UNSW, Sydney, Australia, 5 Nov., 2007.

[10] M.S. Chun, H.I. Cho and I.K. Song. Electrokinetic behavior of membrane zeta potential during the filtration of colloidal suspensions. Desal., 148 (2002) 363. 